АНАЛИЗ СОВРЕМЕННОГО УРОВНЯ ТЕХНОЛОГИЙ ФИЛЬТРАЦИИ ОХЛАЖДАЮЩЕЙ ЖИДКОСТИ АВТОТРАНСПОРТНЫХ ДВИГАТЕЛЕЙ

Драгомиров Сергей Григорьевич доктор технических наук, профессор Владимирский государственный университет им. А.Г. и Н.Г. Столетовых (ВлГУ), г.Владимир Эйдель Павел Игоревич инженер

ООО «НТЦ «АвтоСфера» при ВлГУ», г.Владимир Гамаюнов Антон Юрьевич инженер

ООО «НТЦ «АвтоСфера» при ВлГУ», г.Владимир Драгомиров Михаил Сергеевич кандидат технических наук, ООО «НТЦ «АвтоСфера» при ВлГУ», г.Владимир Кулешов Иван Викторович магистр техники и технологии ООО «НТЦ «АвтоСфера» при ВлГУ», г.Владимир

\title{
ANALYSIS OF THE CURRENT LEVEL OF TECHNOLOGY COOLANT FILTRATION AUTOTRANSPORT ENGINES
}

\author{
Dragomirov Sergei \\ doctor of engineering, professor, \\ Vladimir State University, Vladimir \\ Eydel Pavel \\ engineer, \\ LLC "STC "AutoSphere" at Vladimir State University", Russia \\ Gamayunov Anton \\ Engineer, \\ LLC "STC "AutoSphere" at Vladimir State University", Vladimir \\ Dragomirov Michael \\ candidate of technical Sciences \\ LLC "STC "AutoSphere" at Vladimir State University", Vladimir \\ Kuleshov Ivan \\ master of engineering and technology \\ LLC "STC "AutoSphere" at Vladimir State University", Vladimir \\ DOI: $10.31618 /$ nas.2413-5291.2020.1.57.254 \\ АННОТАЦИЯ*
}

Рассматриваются современные технологии и средства фильтрации охлаждающей жидкости автотранспортных двигателей. Дан сравнительный анализ применяемых устройств и приведены их рабочие характеристики. Описаны перспективные подходы к очистке охлаждающей жидкости. Сделан вывод о широких перспективах гидроциклонных устройств для эффективной очистки охлаждающей жидкости автотранспортных двигателей.

\section{ABSRACT}

The article deals with modern technologies and means of filtering the cooling liquid of autotransport engines. A comparative analysis of the devices used is given. Their performance characteristics are given. Promising approaches to cleaning the coolant are described. The conclusion is made about the wide prospects of hydrocyclone devices for effective cleaning of the coolant of autotransport engines.

Ключевые слова: автотранспортные двигатели; охлаждающая жидкость; загрязнения; очистка; фильтрация; фильтры; гидроциклонные устройства.

Keywords: autotransport engines; coolant filtration; impurity; liquid cleaning; coolant filters; hydrocyclone devices.

В области систем жидкостного охлаждения загрязнение охлаждающей жидкости (ОЖ) и автотранспортных поршневых двигателей системы в целом. критически острой проблемой является

* Данное исследование выполнено в рамках реализации инновационного Проекта «Разработка, изготовление и испытания опытного образца фильтра охлаждающей жидкости на основе моделирования гидравлических и сепарационных процессов" (договор № 2914ГС1/45450) Программы СТАРТ 
Актуальность решения проблемы загрязнения ОЖ автотранспортных поршневых двигателей обусловлена структурными и конструктивными усложнениями их систем жидкостного охлаждения (СЖО) при одновременном повышении требований к их надежности и теплоотводящей функции в процессе непрерывного форсирования двигателей $[1,2]$.

Данные по эксплуатации автотранспортной техники показывает, что от 25 до $40 \%$ неисправностей и отказов двигателей приходится на СЖО [3,4]. Чаще всего неполадки в системе охлаждения появляются уже после $150 \ldots 200$ тыс. км пробега автомобиля. У двигателей тяжелых грузовиков (а также автобусов), работающих обычно с 70...85\% нагрузкой, из-за более тяжелых условий работы неполадки могут возникнуть уже после $500 \ldots 700$ часов эксплуатации. Эти неисправности и отказы в большинстве случаев обусловлены загрязнениями ОЖ.

В зарубежной практике очистки ОЖ пошли по шаблонному пути использования фильтров традиционной конструкции, подобных тем, которые применяются для фильтрации моторного масла (с картонным, синтетическим или сетчатометаллическим фильтрующими элементами). Эти фильтры характеризуются невысокой эффективностью, сложностью конструкции, необходимостью специального установочного места на двигателях.

Среди публикаций по этой тематике выделяются три зарубежные работы [5-7], действительно обладающие научной ценностью. Bce остальные зарубежные публикации носят неглубокий информационно-описательный, либо рекламно-ознакомительный характер. В России научные публикации по этой тематике до последнего времени практически отсутствовали и НИОКР не проводились.

Высокоэффективная фильтрация ОЖ действительно является сложной технической задачей в связи с тремя обстоятельствами:

- расходы ОЖ в контуре системы охлаждения могут достигать у двигателей легковых автомобилей величины $100 \ldots 150$ л/мин., у двигателей грузовых автомобилей - 250...350 л/мин.;

- рабочие температуры ОЖ составляют + $80 \ldots 105^{\circ} \mathrm{C}$ (кратковременно до $+125^{\circ} \mathrm{C}$ );

- современные антифризы представляют собой агрессивные жидкости (смесь воды с этиленгликолем или пропиленгликолем), что предъявляет особые требования к материалам фильтра.

Эти обстоятельства делают весьма сложной задачу высокоэффективной фильтрации ОЖ на борту автотранспортного средства. Значительные расходы агрессивной жидкости при высокой температуре довольно сложно фильтровать с высокой эффективностью, не снижая при этом пропускную способность фильтра.

Именно этим, видимо, и объясняется нерешенность проблемы высокоэффективной фильтрации ОЖ автотранспортных двигателей до настоящего времени.

На сегодняшний день, существующие и производимые устройства для очистки ОЖ, можно разделить на три группы в зависимости от применяемой технологии:

- неразборные фильтры охлаждающей жидкости традиционной конструкции (типа spineon) с фильтрующим элементом из микропористого картона, химического волокна или сетки из нержавеющей стали;

- разборные фильтры с фильтрующим элементом в виде металлической сетки;

- гидроциклонные фильтры-сепараторы, основанные на модифицированном гидроциклонном принципе работы, не имеющие фильтрующего элемента как такового.

Среди этих групп выделяется эффективное, простое и надежное решение проблемы очистки ОЖ [8], основанное на модифицированном гидроциклонном способе очистки жидкостей.

Неразборные фильтры охлаждающей жидкости (ФОЖ) [3,9] зарубежных компаний (Fleetguard, Donaldson, Baldwin, Hengst, WIX и др.) представляют собой по конструкции аналоги традиционных масляных фильтров. За рубежом такие фильтры устанавливаются уже более 70 лет на некоторые модели двигателей, работающих в тяжелых эксплуатационных условиях (тяжелые грузовики, карьерные самосвалы, строительнодорожные машины и т.п.).

Bсе выпускаемые на сегодняшний день подобные ФОЖ по конструкции являются несколько модифицированными аналогами традиционных масляных фильтров (рис. 1) [3,9,10]. В России подобные фильтры производятся по зарубежным лицензиям, собственных конструкций до последнего времени не было. 


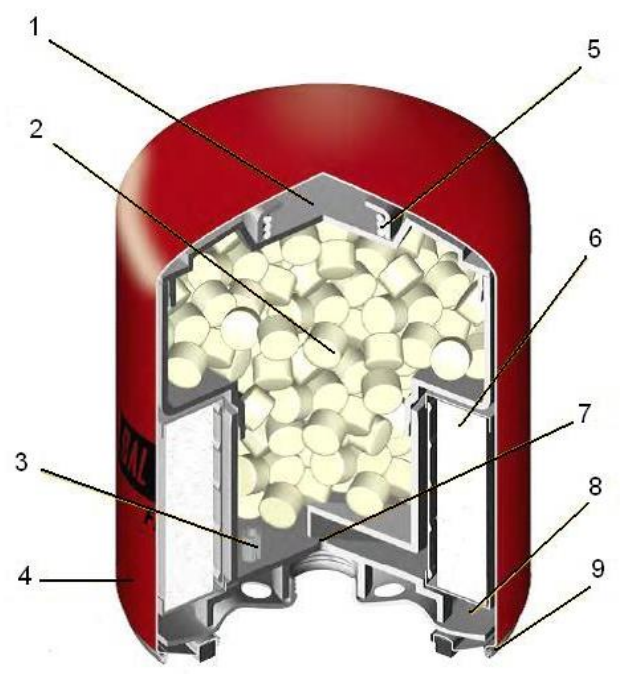

Такие ФОЖ устанавливаются на специальное посадочное место (аналогично масляному фильтру) в блоке двигателя. В зоне этого посадочного места в блоке двигателя выполнены каналы для подвода и отвода ОЖ. Следует отметить, что магистраль для установки такого ФОЖ является байпасной, т.е. через неё проходит только около 10\% (по данным производителей) всего теплоносителя, подаваемого жидкостным насосом СЖО.

Эти фильтры обеспечивают улавливание частиц загрязнений более $30 \ldots 50$ мкм (в зависимости от фирмы-производителя) с вероятностью 98\%. Межсменный срок службы подобных фильтров составляет 1 год (или 150...200 тыс. км пробега автомобиля, или 4000 часов его работы). Они рассчитаны на одноразовое применение, после чего должны утилизироваться.

В качестве вещества специальных присадок, находящихся в виде гранул в корпусе фильтра, различные фирмы используют разные составы: соли азотистой и борной кислот или соли фосфорной, азотистой и молибденой кислот. Каждая из фирм-производителей использует свой состав присадок и по-своему их обозначает $[3,9,10]$ - BTE, BTE-Plus, DCA-2, DCA-4, SCA и др.

В процессе работы фильтра эти гранулы медленно растворяются в антифризе, восстанавливая и улучшая его физико-химические свойства.

Следует отметить, что иногда подобные ФОЖ выпускаются без химических присадок в виде гранул внутри фильтра.

По нашим данным (эксперименты и компьютерное моделирование) через подобные ФОЖ пропускается менее $1 \%$ от всего основного потока ОЖ. Это объясняется наличием у фильтров специального жиклера 7 (см. рис. 1), имеющего диаметр 3...4 мм (в зависимости от производителя). Этот жиклер устанавливается для того, чтобы замедлить и растянуть во времени поступление
Рисунок 1. Конструкциия типичного фильтра охлаждающей жидкости фирмы Baldwin: 1 пластиковая камера для хранения капсул; 2 капсуль (грануль) из специальной присадки к ОЖ; 3 - дросселирующций канал для регулирования подачи присадки; 4 - металлический корпус с эпоксидным покрытием; 5 - пружина; 6 - синтетический фильтрующий элемент; 7 -жиклер (у разных производителей - диаметр 3...4 мм), ограничивающий поток ОЖ через фильтр; 8 стальное основание с резьбовым отверстием по иентру; 9 - двойной закаточный шов, герметично соединяющий основание 8 с корпусом 4

химических присадок в объем антифриза в системе охлаждения.

Таким образом, можно считать, что подобные фильтры не столько выполняют функцию фильтрации, сколько служат в качестве носителей описанных химических присадок для улучшения физико-химических свойств антифризов. Также эти фильтры принципиально не могут быть полнопоточными, т.к. при их полном засорении прекратится циркуляция ОЖ.

Следует отметить, что такие ФОЖ по мере загрязнения в процессе эксплуатации увеличивают свое сопротивление при одновременном ухудшении улавливающей способности. В предельном случае загрязнения они вообще перестают пропускать ОЖ через фильтрующий элемент.

Разборные фильтры с фильтрующим элементом в виде сетки [11] встречаются относительно редко. В качестве примеров можно привести (рис.2) фильтры фирмы Valeo (Франция) для двигателей автобусов Setra, фильтры фирмы Gano (США) [12] для автотранспортных двигателей и фильтры фирмы Guidi (Италия) [13] для двигателей речной техники.

Подобные фильтры имеют практически одну и ту же простейшую конструкцию - фильтрующий элемент в виде металлической сетки (латунь, нержавеющая стать) выполняется в форме конуса или цилиндра. Размер ячеек такой сетки составляет примерно от 300 до 400 мкм. Загрязнения, не проходящие через эту сетку, удерживаются и остаются внутри конуса или цилиндра. При полном загрязнении фильтра требуется его разборка для очистки.

Преимуществами фильтров второй группы (по сравнению с конструкциями первой группой) являются: возможность полнопоточной фильтрации; разборная конструкция и возможность многократного применения; удобство монтажа на любом участке гидравлического контура СЖО. 


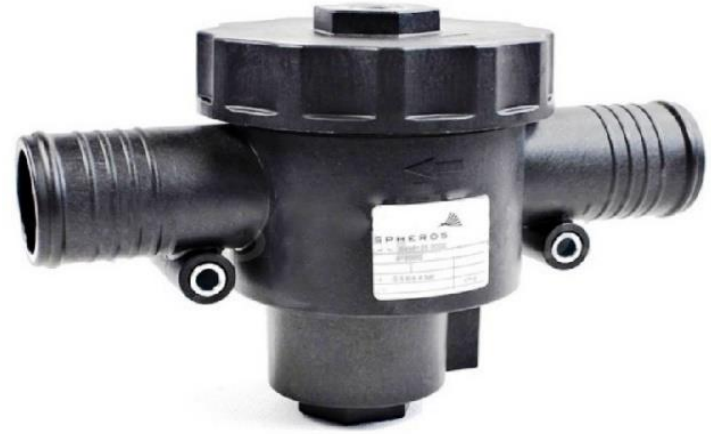

a)

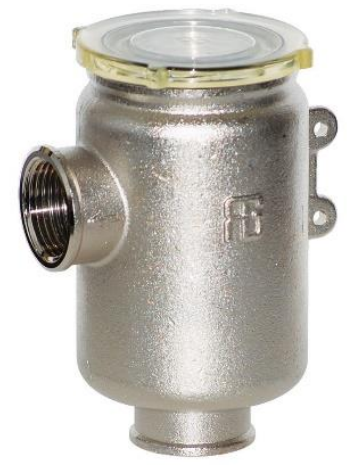

в)

К недостаткам этих фильтров можно отнести: невозможность улавливания частиц с размерами $<300$ мкм; необходимость частой очистки фильтрующего элемента от загрязнений; опасность полного загрязнения фильтра, что может привести к серьезным последствиям, вплоть до выхода двигателя из строя.

Общее свойство фильтров ОЖ первой и второй групп - это увеличение гидравлического сопротивления по мере загрязнения фильтрующих элементов.

В целом технологии фильтрации ОЖ через пористые материалы (микропористый картон, химические волокна) или металлические сетки нельзя считать перспективными. Это объясняется тем, что в процессе очистки ОЖ фильтрующие элементы подобного типа быстро засоряются и существенно уменьшают количество пропускаемой жидкости. В предельном случае они вообще перестают пропускать жидкость.

Кроме этого, из-за быстрого загрязнения подобные фильтры ОЖ требуют замены или очистки. В связи с этим их обычно устанавливают в байпасных магистралях СЖО, что позволяет снизить риск прекращения тока охлаждающей жидкости. При этом неполнопоточная фильтрация

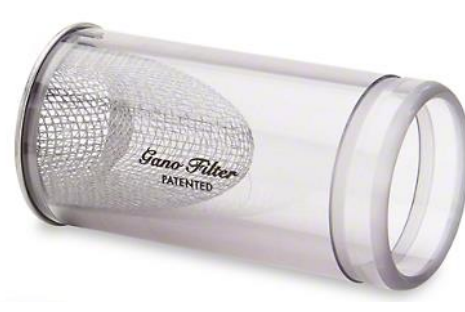

б)

Рисунок 2. Разборные фильтрыс с фильтрующим элементом в виде сетки: а) фильтр ОЖ фирмы Vаlео для двигателя автобуса Setra; б) - фильтр фирмы Gапо (США) для автотранспортных двигателей; в)

- фильтр фирмы Guidi (Италия) для двигателей речных судов

ОЖ (в байпасном канале) не отличается высокой эффективностью.

Гидроциклонные фильтры-сепараторы (ГФС), отнесенные к третьей группе, в принципе свободны от недостатков фильтров первых двух групп.

В гидроциклонном фильтре-сепараторе (рис.3) [8] поток антифриза с твердыми частицами загрязнений поступает в закручивающий аппарат 1 через тангенциальный вход, в результате чего происходит закручивание потока. При прохождении закрученного потока через конусную сепарирующую чашку 2, под действием центробежных сил твердые частицы отбрасываются через улавливающие окна в отстойник 3 и там оседают. Принцип действия ГФС, аналогичен принципу действия гидроциклонов - отделение твердых частиц загрязнений от потока ОЖ происходит под действием центробежных сил (рис. 3б).

Следует отметить разницу в конструкциях этих двух устройств. Основное отличие фильтрасепаратора от классического гидроциклона заключается в наличие улавливающих окон, расположенных в стенках сепарирующей чашки, через которые твердые частицы загрязнений и попадают в отстойник (рис.3). 


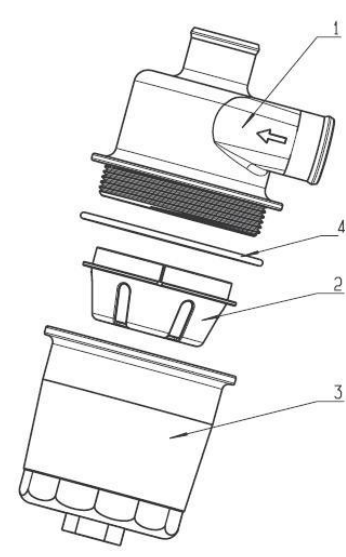

a)

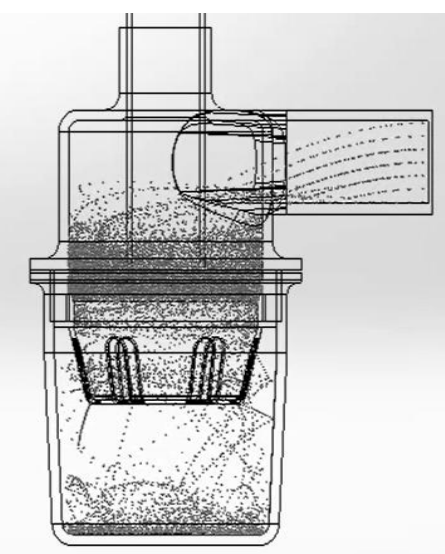

б)

Рисунок 3. Конструкция гидроичиклонного фильтра-сепаратора (а) и его принции действия (б): 1 закручивающий аппарат; 2 - конусная сепарирующая чашка с улавливающими отверстиями; 3 отстойник; 4 - уплотнительное кольцуо

Кроме этого, ГФС имеет разборную конструкцию, что делает его более компактным и удобным при установке и эксплуатации.

К преимуществам созданного ГФС следует отнести: высокоэффективную полнопоточную фильтрацию, обусловленную применением гидроциклонного принципа работы фильтрасепаратора; отсутствие собственно фильтрующего элемента, что упрощает конструкцию, снижает стоимость и существенно повышает пропускную способность фильтра; срок службы ГФС примерно равен ресурсу работы двигателя; ГФС имеет разборную конструкцию, что позволяет его использовать многократно (с периодической очисткой); ГФС обладает конструктивной и технологической простотой, легкостью установки на транспортном средстве (не требует специально выполненного посадочного места на блоке двигателя).

К особенностям работы ГФС можно отнести: зависимость эффективности сепарации от расхода жидкости; при малых расходах жидкости часть твердых частиц загрязнений может не улавливаться и циркулировать в контуре СЖО; не удаляются из потока частицы с плотностью меньше плотности теплоносителя (как правило, это органические частицы).

Проведенный анализ позволяет сделать обоснованный и объективный вывод о том, что созданный во Владимирском государственном университете им. А.Г. и Н.Г.Столетовых гидроциклонный фильтр-сепаратор [8] имеет наилучшие характеристики среди выпускаемых устройств для очистки ОЖ.

Созданный ГФС может найти эффективное применение в СЖО поршневых двигателей различного назначения - автомобилей, автобусов, тракторов, строительно-дорожных

и
лесотехнических машин, армейской техники и др.

Разработки и научные исследования гидроциклонного фильтра-сепаратора являются началом большой работы по становлению нового перспективного направления в области совершенствования автотранспортных поршневых двигателей - высокоэффективной фильтрации охлаждающей жидкости. В результате этой работы на рынке автокомпонентов должны появиться простые, недорогие, надежные и высокоэффективные инновационные гидроциклонные охлаждающей жидкости. фильтры-сепараторы

\section{Список литературы}

1. Системы охлаждения поршневых ДВС: монография / Иванов И.Е. и др. - М.: МАДИ, 2015. $-168 \mathrm{c}$.

2. Системы охлаждения тракторных и автомобильных двигателей. Конструкция, теория, проектирование / Якубович А.И. и др. - Минск: Новое знание; М.: ИНФРА-М, 2014. - 473 с.

3. Руководство по продуктам для системы охлаждения. - Cummins Filtration, 2009. - 8 с.

4. Engine cooling. - Behr Hella Service GmbH., 2008, $52 \mathrm{pp}$.

5. Hudgens R.D., Hercamp R.D. Filtration of Coolants for Heavy Duty Engines. - SAE Techn. Pap. Ser. № 881270 . - 17 pp.

6. Eaton E.R., Duvnjak E. Examinatoins of Extended Life Heavy Duty Engine Coolant Filters. SAE Techn. Pap. Ser. № 2004-1-0157. - 10 pp.

7. Hudgens R.D., Hercamp R.D. An Overview of Onboard Coolant Filtration for Heavy Duty Diesel Engines. - SAE Techn. Pap. Ser. № 2005-01-2014. - 16 pp.

8. Патент РФ на изобретение № 2625891. Гидроциклонное устройство для очистки от твердых частиц загрязнений охлаждающей жидкости поршневых двигателей // Драгомиров С.Г., Драгомиров М.С., Эйдель П.И., Гамаюнов А.Ю., Селиванов Н.М. - 2017. - 10 с.

9. Engine Liquid Filtration. - Minneapolis: Donaldson Company Inc., 2014, 156 pp.

10. Техническая брошюра по фильтрам. - MS Motorservice Int. GmbH, 2014, 48 c.

11. Антропов Б. С. Защита радиаторов системы охлаждения двигателей от продуктов накипи и коррозии / Антропов Б. С., Бодров В. А., Басалов И. 
С. // Вестник АПК Верхневолжья. - 2014. - №4. C.82-84. 12. https://ganofilters.com
13. strainers https://catalogue.guidisrl.it/en/54-water-

\title{
СИММЕТРИЯ, АСИММЕТРИЯ И ДИССИМЕТРИЯ УЗОРОВ, ОРНАМЕНТОВ АЗЕЕРБАЙДЖАНСКИХ КОВРОВ
}

\author{
Кязим-Заде Айдын Кязим \\ кандидат технических наук, дочент \\ Азербайджанский Университет Архитектуры и Строительства
}

2. Баку

\section{SYMMETRY, ASYMMETRY AND DISSYMETRY PATTERNS, ORNAMENTS OF AZERBAIJANI CARPETS}

\author{
Kazim-zade Aydin Kazim \\ Candidate of Technical Sciences, Associate Professor \\ Azerbaijan University of Architecture and Construction \\ Baku city
}

\begin{abstract}
АННОТАЦИЯ
В статье исследуется симметрия, асимметрия и диссиметрия, присущие азербайджанским узорам, орнаментам и коврам ручной работы, а также ковры в целом. Данные характеристики являются одними из основных информативных признаков азербайджанских ковров и их узоров. Проведен сравнительный анализ на симметричность, на основании которого в дальнейшем происходит распознавание узоров и ковров в целом.
\end{abstract}

\section{ABSTRACT}

The article examines the symmetry, asymmetry and dissymmetry inherent in Azerbaijani patterns, handmade carpet ornaments, as well as carpets in general. These characteristics are one of the main informative features of Azerbaijani carpets and their patterns. A comparative analysis of symmetry is carried out on the basis of, which further recognition of patterns and carpets as a whole occurs.

Ключевые слова: ковер, орнамент, узор, симметрия, асимметрия, диссиметрия, информативные признаки, распознавание

Keywords: carpet, ornament, pattern, symmetry, asymmetry, dissymmetry, informative features, recognition

1.Введение. Слово «симметрия» пришло к нам из Древней Греции, и означает пропорциональность, одинаковость в расположении частей. Симметрия окружает нас всюду. Все живое вокруг нас люди, земные и морские животные, птицы, насекомые в той или иной степени можно отнести к какому -либо типу симметрии. Симметричны кристаллы химических элементов, все виды живых существ, листья деревьев, кустарников, их плоды и т.д. Существует некоторое количество типов симметрии. Все они классифицированы по определенным математическим правилам. Но к основным типам симметрии относятся центральная, осевая (зеркальная), радиальная. Небольшое отклонение от идеальной симметрии приводит к асимметрии объекта, и это порой добавляет неповторимые красоты. Но, кроме симметричных и ассиметричных встречаются фигуры с диссиметрией.

2.Постановка задачи. В работе [1,c,17] были определены информативные признаки ковровых узоров, орнаментов, а также ковровых изделий в целом. К ним относятся: форма ковра (прямоугольная, квадратная, овальная, круглая и т.д.); геометрические размеры (длина, ширина, радиус и т.д.); имя узора (декора); количество контуров в узоре; цветовая гамма узора; центр тяжести узора; наличие или отсутствие симметрии.

Проведение исследований по классификации узоров, орнаментов и азербайджанских ковров ручной работы по информативным признакам наличия симметрии, асимметрии и диссиметрии позволит облегчить процесс распознавания, идентификации узоров [1,c.17, 2,c.27], орнаментов и ковра в целом.

3.Решение. Качество ковров определяется рядом характеристик. Элитный ковер обязательно изготавливается вручную, имеет высокую узелковую плотность (от 500 тыс. узелков на кв. метр до 2 миллионов), качество материала (используется дорогая тончайшая шерсть горных пород овец) и т.д. Большое значение имеет рисунок ковра, его цветовая гамма. Именно эти показатели, после указанных технических характеристик, и представляют собой факторы выбора ковра для определенного помещения, способного преобразовать пространство, придать тепло и уют. При грамотном выборе и размещении ковра его узоры будут радовать глаз, вписываться в интерьер всего помещения.

Коврам и украшающих их узорам присуще геометрическая симметрия. Причем это касается ковров производителей всех стран мира. Композиция ковров обычно состоит из двух частей 